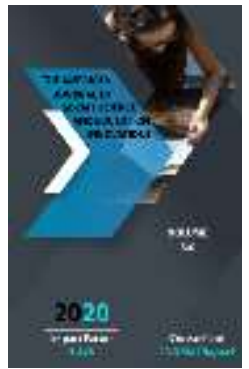

Journal Website: http://usajournalshub.c om/index,php/tajssei

Copyright: Original content from this work may be used under the terms of the creative commons attributes 4.0 licence.

\section{The Role And Importance Of Chemical Knowledge In Biological Education}

\author{
Akhmadzhon Mirzaevich Jumanov \\ Associate Professor, Kokand State Pedagogical Institute Named After Mukimiy, Uzbekistan
}

\title{
ABSTRACT
}

This article highlights the importance of chemical science in interaction with biological Sciences and the training of future biology teachers in higher educational institutions on their basis.

\section{KEYWORDS}

Natural science worldview, integration, Chemistry course, interdisciplinary communication, interaction of chemistry and biology, synchronous and asynchronous communications.

\section{INTRODUCTION}

It is known that although the science of chemistry was formed in the last centuries after the ancient world, neither physics nor biology could develop without its help $[1,36]$. Many ideas have been expressed about the natural science worldview, but, unfortunately, physical chauvinism and biological reductionism have reached the point of being eradicated on both sides.
While physicists argue that chemistry is a science embedded in our fields, chemistry can survive as a separate branch of physics, biologists argue that the chemical form of movement of matter has become an integral part of biological form [3,76-83]. The relationship between chemistry and biology has evolved from the ancient world to the 
Stone Age, Bronze Age, Iron Age, and finally to modern civilization.

\section{THE MAIN FINDINGS AND RESULTS}

Main part Teaching chemistry and biology is an important part of the problems of the system of continuing education in the Republic of Uzbekistan. The closest related sciences in the natural sciences are chemistry and biology:

1. All representatives of the biosphere have a chemical composition that cannot be interpreted without a chemical interpretation.

2. The basis of biological processes is chemical changes. Modern biological knowledge cannot be given without knowing the place of chemical reactions in living systems.

3. Chemistry cannot be fully studied without physical postulates and laws.

While chemists provide physicists with information about atoms and ions, radicals and molecules, coordination and chelate compounds, as well as isotopes and isobars, biologists provide information about the chemical elemental composition of living matter, the composition and structure of living molecules, the mechanisms of transformation, metabolism and energy exchange, assimilation and dissimilation (anabolism and catabolism), synthesis, destruction and regeneration of proteins and other biological molecules.Biosynthesis and decomposition of biological molecules, the chemical nature of biologically active substances, changes in plastic and energetic substances in life, provide all information about the chemical details of all substances that provide processes [6, 31-34].

Biologists cannot understand the essence of life processes without the help of chemists.
The Nobel Prize laureate, British biochemist J. Watson and the first American theoretical physicist F. Crick, who created a macromolecular model of deoxyribonucleic acid with a double helix, described in detail the differences in how chemists and biologists think about these discoveries: "In England, maybe and all over the world, most biologists, especially botanists and zoologists, are a goofy public"

It's no secret that the interaction of chemists and biologists has led to universal inventions and discoveries. An example of this is the work of $\mathrm{H}$. Krebs, who opened the main vessel of metabolism and energy in living organisms, the mechanism of metabolism of $\mathrm{di}$ - and tricarboxylic acids, the citric acid cycle, the center of basic metabolic metabolism and made discoveries in the field of physiology and medicine in 1953 and received the Nobel Prize premium [4,32]. The need for chemical knowledge for biologists to properly understand the universe is an absolute fact. Everything in biology and the essence of the phenomenon cannot be explained without a chemical basis and chemical factors. Therefore, the scientific cooperation of chemists and biologists should be interpreted as a very important phenomenon from both scientific, pedagogical and socio-humanitarian points of view.

Relationship issues in the field of chemistry and biology of higher education are insufficiently studied $[1,38]$.

Determining the role and place of chemical knowledge in the process of training biology teachers is an urgent pedagogical problem. Its study, analysis and development of practical recommendations at the level of higher educational institutions of the Republic of Uzbekistan are important scientific and 
pedagogical issues $[6,65-71$.$] . To solve these$ scientific and pedagogical problems, pedagogical research was carried out on the integrated teaching of chemistry in the field of biological education in higher educational institutions (pedagogical institutes and universities). Methodological developments, teaching aids and textbooks with integrative content were developed and applied to the educational process[8, 78-83].

\section{RESULTS AND DISCUSSION}

An analysis of current state educational standards (GOS) and the content of education in the field of education "Methods of Teaching Chemistry and Biology" show that there is a whole system of concepts that is universal for the sciences of the natural science cycle: 1 . Substances and their elemental components. 2. Elemental units of substances involved in occurring phenomena and processes. 3. Material units that provide the relationship of animate and inanimate nature. We consider it appropriate to carry out inter-subject communications in the teaching of chemical and biological disciplines in the following areas:

1. The structure of substances and mechanisms of occurring phenomena and processes that are universal for chemical and biological sciences.

2. Generality in the essence of the laws available in the scientific foundation of chemistry and biology.

3. The relationship and complementarily of theories of chemistry and biology.

4. The use of chemical knowledge to explain the mechanisms of biochemical processes.

5. The use of biological knowledge for the formation of chemical, environmental and environmental concepts.
6. The mutual application of the methods, means and methods of these sciences in the teaching of chemistry and biology. Inter-subject communications of chemistry and biology, as a powerful lever, can fruitfully serve to form a naturalscience picture of the world and a holistic and general scientific worldview [7; p.589].

7. Interdisciplinary connections at the level of facts (actual) are the establishment of the similarity of facts, the use of general facts studied in chemistry, biology courses, and their comprehensive consideration in order to generalize knowledge about individual phenomena, processes and objects of nature. So, in teaching biology and chemistry, future teachers can use data on the chemical composition of the human body. Conceptual inter-subject communications are the expansion and deepening of the attributes of subject concepts and the formation of concepts common to related subjects (general subjects). The general concepts in the courses of the natural science cycle include the concepts of the theory of the structure of substances - body, substance, composition, molecule, structure, property, as well as general concepts phenomenon, process, energy, etc.

\section{CONCLUSION}

These concepts are widely used in the study of the processes of assimilation and dissimilation. Moreover, they deepen, concretize on biological material and acquire a generalized, general scientific character. A number of general biological concepts reflect 
such complex processes of living nature that it is impossible to disclose even at the first stage of their introduction without involving chemical concepts. So, the concept of photosynthesis has developed in science as a result of studying this process by plant physiology and borderline sciences biophysics and biochemistry. Theoretical interdisciplinary communication is the development of the basic principles of general scientific theories and laws studied in the lessons on related subjects, with the aim of assuming students a holistic theory.

\section{REFERENCES}

1. Omonov H.T. Philosophical and pedagogical bases of chemistry education and issues of its improvement: Ped.f.d. dis. ... Tashkent: TDPI named after Nizami, 1995. - p. 265.

2. Omanov H.T. Specificity of the chemical form of motion of matter. Author's abstract. Diss ... Candidate of Philosophy. - Moscow: MGPI im. V.I. Lenin, 1987. p.16.

3. Geisenberg V. Conversations about the relationship between biology, physics and chemistry // Journal "Nature". 1979. №4. pp.76-83.

4. Omonov H.T. Qorabolaev B.Q. Nobel Prize and its award-winning chemists Tashkent: "Knowledge Publishing House", 1993. - p. 32.

5. A. M. Jumanov. Chemistry. - Tashkent: Sparks of Literature, 2019.-230 p.

6. Jumanov A.M. Some issues of teaching the course "Inorganic Chemistry" for biology education // Bulletin of Khorezm Mamun Academy. - Khorezm, 2011.-№2. pp. 65-71.

7. Jumanov A., Nishonov M., Sodikov M. Inter-subject communications in the teaching of chemistry in the preparation of a future biology teachers. Academicia An InternationalMultidiscipl in ary Re search Journal (Double Blind Refereed \& Reviewed International Journal). - pp. 585-590.

8. Nishonov M., Jumanov A. Study of the pedagogical effectiveness of the content of the methodology of teaching chemistry // Scientific Bulletin of FerSU, 2016, №1. - pp. 78-83. 